\title{
Studies on Crude Drugs Effective on Visceral Larva Migrans. I. Identification of Larvicidal Principles in Betel Nuts
}

\author{
FumiYuki KiUchi, ${ }^{a}$ NaOShi Miyashita, ${ }^{a}$ Yoshisuke Tsuda,,${ }^{* a}$ \\ KaORU KONDO, ${ }^{b}$ and HiroyuKI YoshimURA ${ }^{b}$ \\ Faculty of Pharmaceutical Sciences, Kanazawa University, ${ }^{a}$ and School of Medicine, \\ Kanazawa University, ${ }^{b}$ 13-1 Takara-machi, Kanazawa 920, Japan
}

(Received January 10, 1987)

\begin{abstract}
Larvicidal principles obtained from the $50 \%$ aqueous acetone extract of betel nuts (Areca catechu) were revealed to be a mixture of fatty acids. They were identified by GC-MS analysis as lauric, myristic, palmitic, and oleic acids. Determination of the larvicidal activities of fatty acids and aliphatic alcohols with various alkyl chain lengths, and of analogous compounds with various functional groups, suggested that the balance between hydrophilicity and hydrophobicity is important for the larvicidal activity.
\end{abstract}

Keywords - anthelmintic; Areca catechu; fatty acid; tannin; aliphatic alcohol; betel chewing; Toxocara canis; larva; larvicide

There are many anthelmintics effective against parasites living in the gastrointestinal tract. ${ }^{1)}$ However, very few are known to be effective against parasitic diseases caused by nematodes parasitizing tissues. This presents a problem, since reports on the occurrence of visceral larva migrans, in which pathogenic larvae of a nematode migrate through blood vessels to the liver, lung, eyes, brain or muscles, and cause persistent hypereosinophilia together with hepatomegaly or pneumonitis, ${ }^{2)}$ have been increasing in recent years. In most cases, the pathogenic helminth was derived from dogs or cats kept as pets. No anthelmintic is known to be certainly effective against this disease. With the aim of finding a new anthelmintic effective against parasites living in tissues, we started in vitro screening tests of medicinal drugs used in traditional medicines as larvicides against the larva of dog round worm, Toxocara canis, which is a common pathogenic parasite in visceral larva migrans. This larva is useful for bioassay because it is highly resistant to drugs and can be kept in synthetic medium for several months. ${ }^{3)}$ In this report, we describe the identification of larvicidal principles from betel nuts, edible endosperm of the palm, Areca catechu L. (檳榔子). In South East Asia, many people chew this nut with betel leaves as a luxury. The anthelmintic effect of this nut is interesting from the viewpoint of prevention of parasitic diseases.

\section{Materials and Methods}

Melting points were taken on a Yanagimoto micro hot-stage melting point apparatus, and are uncorrected. Infrared (IR) spectra were taken on a JASCO A-202 spectrometer and are given in $\mathrm{cm}^{-1}$. Proton nuclear magnetic resonance $\left({ }^{1} \mathrm{H}-\mathrm{NMR}\right)$ spectra were measured in $\mathrm{CDCl}_{3}$ solution with tetramethylsilane as an internal standard on a JEOL FX-100 spectrometer. Mass spectra (MS) and gas liquid chromatography-mass spectra (GC-MS) were taken on a Hitachi M-80 machine. Gas liquid chromatography (GLC) analyses were performed on a Shimadzu GC4CMPF instrument with an FID detector using a $1.5 \% \mathrm{OV}-1$ glass column. Fuji-Davison BW-820 MH (silica gel) was used for column chromatography. For thin layer chromatography (TLC), Macherey-Nagel SIL G-25 UV 254 plates were used and spots were observed by spraying $1 \%$ ceric sulfate in $10 \% \mathrm{H}_{2} \mathrm{SO}_{4}$ followed by heating until coloration appeared.

Chemicals - All chemicals were purchased from Nakarai Chemicals Ltd. unless otherwise mentioned. 1- 
Decanamide $^{4)}$ and 1-decanonitrile ${ }^{5)}$ were prepared according to the cited methods. Decylamine was prepared by the reduction of decanamide with $\mathrm{NaBH}_{4}$ in the presence of ethanedithiol. ${ }^{6}$ )

5-Nonyltetrazole ${ }^{7}$ — - 1-Decanonitrile $(940 \mathrm{mg}), \mathrm{NaN}_{3}(1.78 \mathrm{~g})$, and $\mathrm{NH}_{4} \mathrm{Cl}(490 \mathrm{mg})$ were dissolved in dimethylformamide (DMF, $10 \mathrm{ml}$ ) and kept at $140{ }^{\circ} \mathrm{C}$ for $12 \mathrm{~h}$. The reaction mixture was diluted with ethyl acetate (AcOEt), washed with $1 \mathrm{~N} \mathrm{HCl}$, then extracted with $5 \% \mathrm{NaHCO}_{3}$. The aqueous layer was acidified with $\mathrm{HCl}$ and extracted with AcOEt. The extract was washed with brine, dried over $\mathrm{Na}_{2} \mathrm{SO}_{4}$, and concentrated. The residue was recrystallized from hexane to give colorless platelets $\left(437 \mathrm{mg}, 36 \%\right.$ ), mp $57-58^{\circ} \mathrm{C}$. Anal. Calcd for $\mathrm{C}_{10} \mathrm{H}_{20} \mathrm{~N}_{4}: \mathrm{C}, 61.18 ; \mathrm{H}, 10.27$; $\mathrm{N}, 28.55$. Found: C, 61.22; H, 10.37; N, 28.45.

Test Solution-Test samples were dissolved in $0.7 \%$ saline or, in the case of samples not readily soluble in water, dissolved in dimethylsulfoxide (DMSO) and diluted with saline. DMSO showed no effect on the assay up to the concentration of $2 \%(\mathrm{v} / \mathrm{v})$.

Assay Method - The second stage larvae of dog round worm (Toxocara canis) were collected by the method previously described ${ }^{8)}$ and kept in Eagle-MEN medium (Nissui Pharmaceutical Co.) at $37^{\circ} \mathrm{C}$. For one assay, 20 larvae were incubated with the test solution in a Corning cell well at $37^{\circ} \mathrm{C}$ and the behavior of the larvae was observed under a microscope at 1, 3, 6, and $24 \mathrm{~h}$ after the start of incubation. All assays were done in duplicate. The effect of each test material was assessed according to the state of the larvae based on the criteria listed in Table I. The relative movability (RM) value was calculated from Eqs. 1 and 2, and used as a measure of the anthelmintic activity of the test material. Minimal lethal concentration (MLC) was determined as the lowest concentration with an RM value of 0 after $24 \mathrm{~h}$ of incubation.

Extraction and Separation — Cut betel nuts $(250 \mathrm{~g})$ were extracted with three $500 \mathrm{ml}$ portions of $50 \%$ aqueous acetone under reflux for $3 \mathrm{~h}$. After removal of the acetone under reduced pressure, the residual aqueous suspension was extracted with AcOEt to give $7.08 \mathrm{~g}$ of AcOEt extract (fr. B) and a residual fraction (fr. A). Fr. B, after concentration, was extracted with $100 \mathrm{ml}$ of hot hexane (fr. C) and the residual fraction (fr. D) was further partitioned with $\mathrm{CHCl}_{3}: \mathrm{MeOH}: \mathrm{H}_{2} \mathrm{O}=3: 3: 2$ to give frs. $\mathrm{E}$ (aqueous layer) and $\mathrm{F}$ (organic layer). The yield and larvicidal activity of each fraction are shown in Chart 2.

Identification of Larvicidal Principles_-Fr. F (110 mg) was applied to a silica gel column and eluted with AcOEt (fr. G) and MeOH (fr. H) successively. A part of fr. G (10 mg), which showed larvicidal activity, was dissolved in $\mathrm{MeOH}$ and methylated with ethereal diazomethane. GLC and GC-MS analyses showed the presence of lauric, myristic, palmitic, and oleic acids. GC-MS conditions: column, $1.5 \% \mathrm{OV}-1,1 \mathrm{~m}$; column temperature, $100 \rightarrow 220^{\circ} \mathrm{C}$, $5{ }^{\circ} \mathrm{C} / \mathrm{min}$; flow rate, $40 \mathrm{ml} \mathrm{He} / \mathrm{min}$; injector temperature, $235^{\circ} \mathrm{C}$. Peak 1 (methyl laurate), $t_{\mathrm{R}}: 5.3 \mathrm{~min}$. MS $\mathrm{m} / z(\%): 214$ $\left(\mathrm{M}^{+}, 2\right), 183(2), 171(3), 143(3), 129$ (2), 87 (18), 74 (100). Peak 2 (methyl myristate), $t_{\mathrm{R}}: 10.5 \mathrm{~min}$. MS $m / z(\%): 242$ $\left(\mathrm{M}^{+}, 3\right), 211$ (2), 199 (3), 143 (4), 129 (2), 87 (20), 74 (100). Peak 3 (methyl palmitate), $t_{\mathrm{R}}: 15.6 \mathrm{~min}$. MS $\mathrm{m} / z(\%): 270$ $\left(\mathrm{M}^{+}, 4\right), 239(2), 227(3), 149(2), 143$ (4), $135(2), 87$ (17), 74 (100). Peak 4 (methyl oleate), $t_{\mathrm{R}}: 19.4 \mathrm{~min} . \mathrm{MS} \mathrm{m} / z(\%)$ : $296\left(\mathrm{M}^{+}, 1\right), 294(1), 264(2), 222(1), 180(1), 123(2), 110(2), 96(4), 81$ (100).

\section{Results and Discussion}

\section{Extraction of Larvicidal Principles from Betel Nuts}

In the screening test for larvicidal activity of crude drugs used for the treatment of parasitic diseases in traditional medicines, a hot water extract of betel nuts showed only weak anthelmintic activity $\left(\mathrm{RM}=52,10 \mathrm{mg} / \mathrm{ml}, 24 \mathrm{~h}\right.$ incubation). ${ }^{9)}$ However, the $50 \%$ aqueous acetone extract showed strong larvicidal activity with a "burst" effect on dog round worm

TABle I. Criteria for Evaluating Effect on Larvae

\begin{tabular}{lc}
\hline State & Score $(n)$ \\
\hline Moving with whole body & 3 \\
Moving with only a part of body & 2 \\
$\quad$ in the observation period & \\
Immobile but not dead & 1 \\
Dead & 0 \\
\hline
\end{tabular}

$$
\begin{aligned}
& \text { movability index }(\mathrm{MI})=\frac{\sum n N_{n}}{\sum_{i} N_{n}} \\
& N_{n} \text { : number of larvae with the score of } n \\
& \text { relative movability }(\mathrm{RM})=\frac{\mathrm{MI}_{\text {sample }}}{\mathrm{MI}_{\text {control }}} \times 100
\end{aligned}
$$




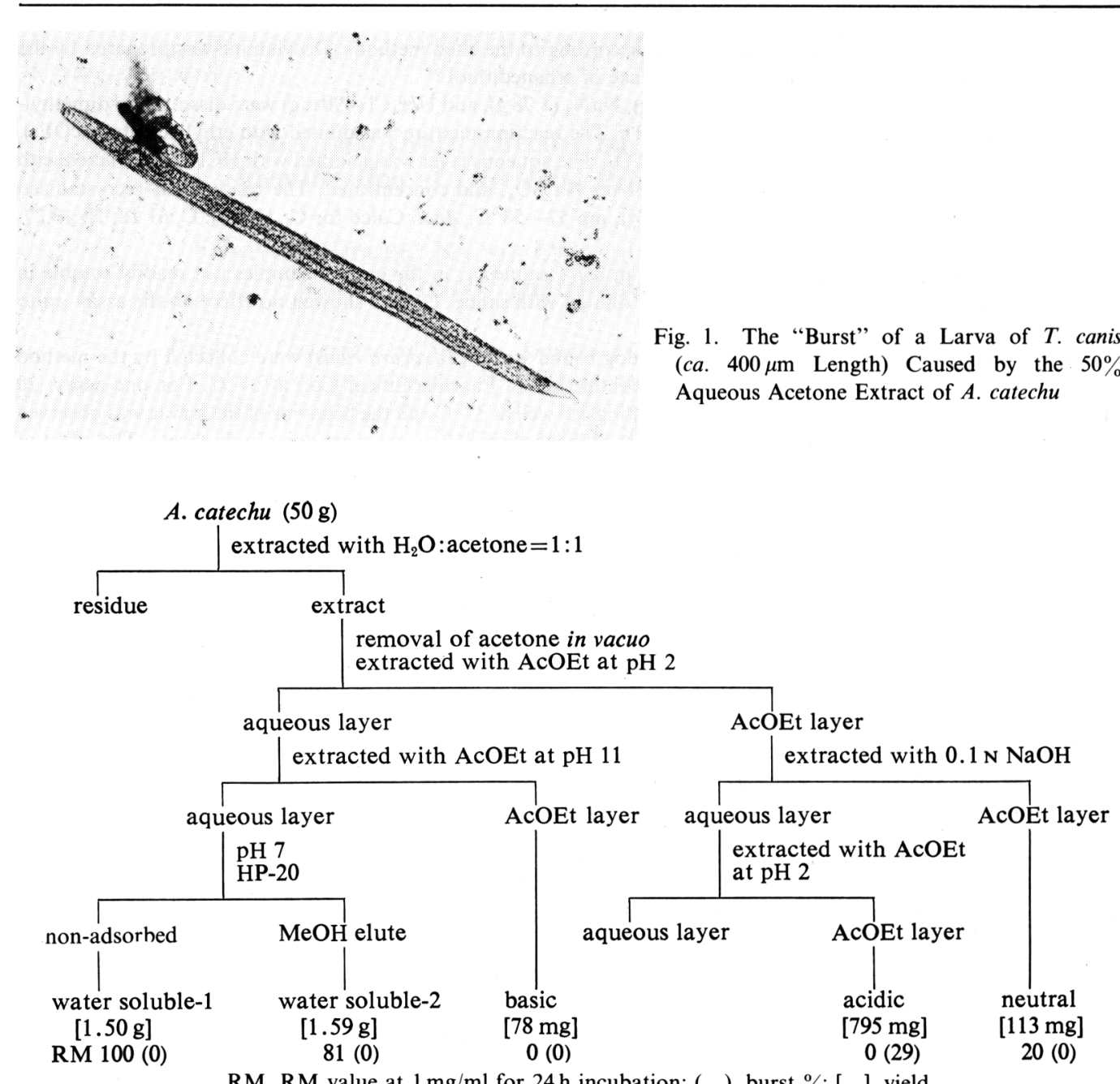

$\mathrm{RM}, \mathrm{RM}$ value at $1 \mathrm{mg} / \mathrm{ml}$ for $24 \mathrm{~h}$ incubation; ( ), burst \%; [ ], yield

Chart 1. Preliminary Test

larvae (Fig. 1). In a preliminary experiment to identify the larvicidal principles, the $50 \%$ acetone extract was fractionated into acidic, basic, neutral, and water-soluble fractions in the usual manner. The water-soluble fraction was passed through a Diaion HP-20 column and eluted with $\mathrm{MeOH}$ to give the non-adsorbed and adsorbed fractions (Chart 1). Among these five fractions, the basic and acidic fractions showed larvicidal activity at a concentration of $1 \mathrm{mg} / \mathrm{ml}$, but the "burst" was observed only in the acidic fraction.

As regards the anthelmintic principle in the basic fraction, arecoline is known to be one of the major constituents of betel nuts. ${ }^{10)}$ In fact, the larvicidal activity of arecoline was $\mathrm{RM}=2$ (at $24 \mathrm{~h}$ incubation) at a concentration of $0.5 \mathrm{mg} / \mathrm{ml}$, though its, hydrobromide showed a paralyzing effect with only a very weak killing activity $(\mathrm{RM}=34)$ on larvae even at a concentration of $1 \mathrm{mg} / \mathrm{ml}$. However, the quantity of the basic fraction was too small to be responsible for the larvicidal activity of betel nuts. Therefore, based on the quantities of the fractions, we concluded that the major constituent(s) responsible for the larvicidal activity of betel nuts is present in the acidic fraction.

\section{Identification of Larvicidal Principles}

To identify the larvicidal principles in the acidic fraction, $50 \%$ aqueous acetone extract of 
betel nuts was fractionated into eight fractions as shown in Chart 2 (see Materials and Methods). Fr. B showed larvicidal and "burst" activity, and was further divided into frs. C and D. Both fractions showed larvicidal activity, whereas only the latter showed "burst" activity. Next, fr. D was fractionated into lipophilic and hydrophilic fractions (frs. F and E). At this stage, only fr. F showed larvicidal activity and fr. E did not show killing activity at a concentration of $1 \mathrm{mg} / \mathrm{ml}$. The "burst" activity seemed to have disappeared. However, when the same amounts of frs. E and F were combined, the "burst" activity was restored. This result suggested that there were at least two substances taking part in the larvicidal and "burst" effects, i.e. compound(s) with only larvicidal activity and compound(s) without larvicidal activity but causing a "burst" in combination with the larvicidal compound(s). The fraction causing the "burst" (fr. E) was rich in tannins. Therefore, some tannins purified from A. catech $u^{11)}$ were assayed for the "burst" effect and some of them were revealed to cause the "burst" in combination with capric (decanoic) acid. Details of the "burst" effect of tannins will be reported elsewhere.

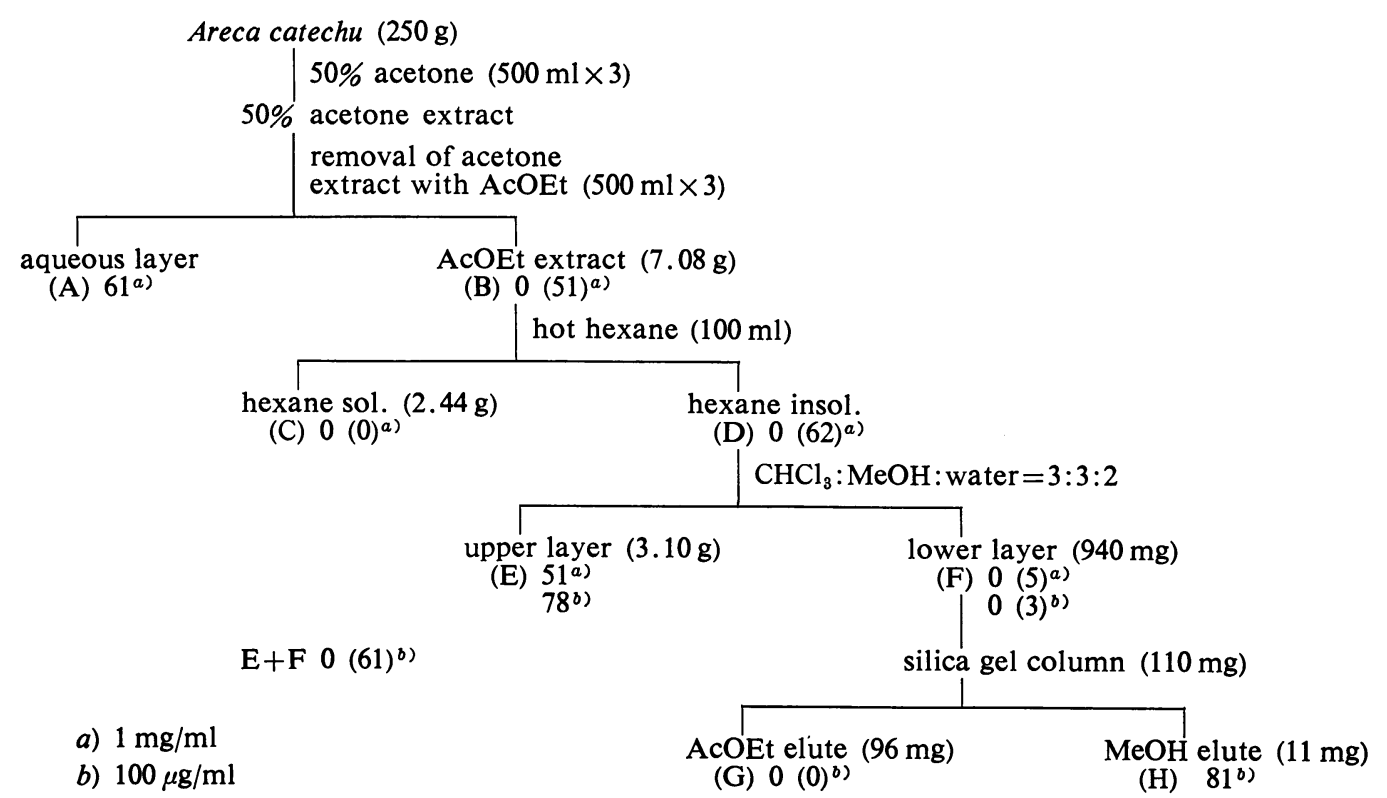

Chart 2. Purification of Larvicidal Principles of A. catechu

For the identification of the constituents responsible for the larvicidal activity, fr. F was subjected to silica gel column chromatography, and the activity was found to be eluted by AcOEt (fr. G). From the ${ }^{1} \mathrm{H}-\mathrm{NMR}$ and MS, the major constituent of this fraction was suggested to be a mixture of fatty acids, so this fraction was treated with diazomethane and subjected to GLC and GC-MS analyses (Fig. 2). GC-MS analysis revealed that this fraction consisted of lauric, myristic, palmitic, and oleic acids in the ratio shown in Fig. 2. The other active fraction (fr. C) was also treated with diazomethane and analyzed by GLC (Fig. 2), and the constituents were found to be very similar to those of fr. G.

\section{Larvicidal Activity of Fatty Acids and Related Compounds}

The major constituents of the larvicidal fractions in betel nuts were found to be fatty acids, so the MLC of straight chain fatty acids of various chain lengths were determined. Interestingly, as shown in Fig. 3, the larvicidal activity of fatty acids depended markedly on the chain length. Fatty acids shorter than heptanoic acid were inactive up to the concentration of 


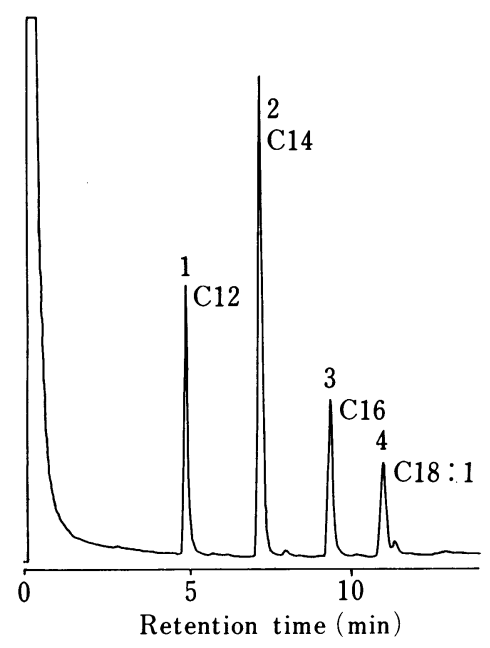

Fig. 2. GLC Analyses of the Active Fractions after Treatment with Diazomethane

Column, $1.5 \%$ OV-1, $1 \mathrm{~m}$; column temp., $100 \rightarrow$ $220^{\circ} \mathrm{C}\left(10^{\circ} \mathrm{C} / \mathrm{min}\right)$; injector temp., $250^{\circ} \mathrm{C}$; flow rate, $60 \mathrm{ml} \mathrm{N} / \mathrm{min}$.

\begin{tabular}{|c|c|c|c|c|}
\hline \multirow{2}{*}{ Peak } & \multirow{2}{*}{$\begin{array}{l}\text { Retention time } \\
\quad(\min )\end{array}$} & \multicolumn{2}{|c|}{ Relative intensity $(\%)$} & \multirow{2}{*}{ Identification } \\
\hline & & Fr. C & Fr. G & \\
\hline 1 & 4.9 & 25 & 29 & Methyl laurate \\
\hline 2 & 7.2 & 45 & 37 & Methyl myristate \\
\hline 3 & 9.4 & 16 & 29 & Methyl palmitate \\
\hline 4 & 11.1 & 14 & 24 & Methyl oleate \\
\hline
\end{tabular}

$1 \mathrm{~mm}$. Between $\mathrm{C}_{8}$ and $\mathrm{C}_{12}$, larvicidal activity increased gradually as the alkyl chain length increased, and the strongest activity was obtained with lauric (dodecanoic) acid (MLC $150 \mu \mathrm{M})$. However, the activity decreased rapidly above $\mathrm{C}_{13}$. Hexadecanoic and octadecanoic acids were inactive, though they are hardly soluble in water and had to be assayed in suspension. Such a "cut-off" of activity has been observed in several biological activities of analogous compounds. ${ }^{12)}$ The phenonenon is related to the partition coefficient of the compounds and can be explained by models in which the concentration of the compound at the active site is governed by the partition coefficient of the compound. ${ }^{13)}$

Next, straight chain aliphatic alcohols, which have a neutral functional group at the end of the alkyl chain, were tested for larvicidal activity (Fig. 3). An analogous relationship between chain length and MLC was obtained, but in this case, tetradecyl alcohol showed the strongest activity (MLC $20 \mu \mathrm{M}$, about one-tenth of that of dodecanoic acid). A similar action curve was reported for the antimicrobial activity of aliphatic alcohols against Clostridium botulinum $^{14)}$ and Streptococcus mutans. ${ }^{15)}$ However, to our knowledge, this is the first report on the anthelmintic activity of fatty acids and aliphatic alcohols against larva of dog round worm.

Since fatty acids and alcohols with long alkyl chains showed strong larvicidal activity, some analogous compounds were also tested for larvicidal activity (Table II). Methyl decanoate and decanonitrile, which have relatively hydrophobic groups at the end of the alkyl chain, were inactive. On the other hand, decylamine, and nonyltetrazole, with hydrophilic groups, were as larvicidal as the acid and the alcohol. The sodium salt of decanoic acid was inactive. Therefore, some balance between the hydrophobicity (length of hydrophobic alkyl chain) and the hydrophilicity of the functional group seems to be essential for the larvicidal activity.

In the South Asia, betel chewing is a common habit. Betel nuts contain large amounts of 


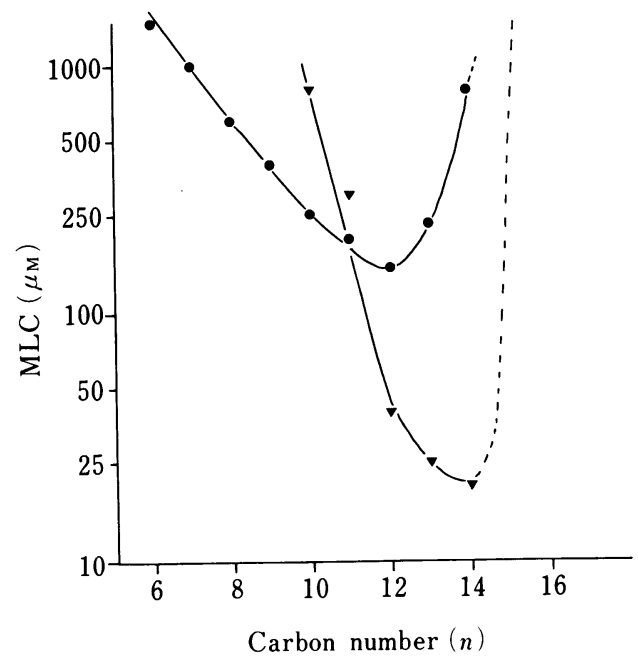

Fig. 3. Minimal Lethal Concentration of Fatty Acids and Aliphatic Alcohols

$-\mathrm{C}, \mathrm{CH}_{3}\left(\mathrm{CH}_{2}\right)_{n-2} \mathrm{COOH}$

$-\nabla-, \mathrm{CH}_{3}\left(\mathrm{CH}_{2}\right)_{n-1} \mathrm{OH}$.

TABLE II. Larvicidal Activity of Decanoic Acid Analogues (RM Value)

\begin{tabular}{lcrrrr}
\hline \hline \multicolumn{1}{c}{ Sample } & Conc. & $1 \mathrm{~h}$ & $3 \mathrm{~h}$ & $6 \mathrm{~h}$ & $24 \mathrm{~h}$ \\
\hline Decanoic acid & $500 \mu \mathrm{M}$ & 0 & 0 & 0 & 0 \\
& $250 \mu \mathrm{M}$ & 71 & 9 & 1 & 0 \\
& $125 \mu \mathrm{M}$ & 96 & 94 & 84 & 82 \\
Sodium decanoate & $1 \mathrm{mM}$ & 99 & 99 & 81 & 78 \\
Methyl decanoate & $1 \mathrm{mM}$ & 94 & 100 & 95 & 87 \\
Decanonitrile & $1 \mathrm{mM}$ & 85 & 102 & 102 & 100 \\
Decanamide & $1 \mathrm{mM}$ & 101 & 101 & 102 & 61 \\
Decylamine & $500 \mu \mathrm{M}$ & 34 & 0 & 0 & 0 \\
& $320 \mu \mathrm{M}$ & 33 & 54 & 74 & 72 \\
Decyl alcohol & $1 \mathrm{mM}$ & 35 & 0 & 0 & 0 \\
Nonyltetrazole & $500 \mu \mathrm{M}$ & 40 & 0 & 0 & 0 \\
& $250 \mu \mathrm{M}$ & 53 & 7 & 0 & 0 \\
& $125 \mu \mathrm{M}$ & 95 & 81 & 59 & 10 \\
\hline
\end{tabular}

fatty acids and tannins. ${ }^{10)}$ In our in vitro assay system, the combination of these compounds showed strong larvicidal activity against larvae of dog round worm. These facts suggested that the widespread habit of betel chewing in the South East Asia may be effective in the prevention of parasitic diseases.

Acknowledgment The authors thank Misses Satomi Nishizawa and Akiyo Uchitani for their technical assistance. F. K. gratefully acknowledges a Grant-in-Aid for Encouragement of Young Scientists (No. 60771851, 1985) from the Ministry of Education, Science and Culture of Japan.

\section{References and Notes}

1) A. G. Gilman, L. S. Goodman, and A. Gilman, "The Pharmacological Basis of Therapeutics," 6th ed., Macmillan Publishing, New York, 1980, Chapter 44.

2) P. C. Beaver, R. C. Jung, and E. W. Cupp, "Clinical Parasitology," 9th ed., Lea \& Febiger, Philadelphia, 1984, p. 325 .

3) T. Oshima, J. Parasit., 47, 652 (1961).

4) R. E. Kent and S. M. McElvain, "Organic Syntheses," Coll. Vol. III, ed. by E. C. Horning, John Wiley and Sons, Inc., New York, 1955, p. 490. 
5) J. A. Krynitsky and H. W. Carhart, "Organic Syntheses," Coll. Vol. IV, ed. by N. Rabjohn, John Wiley and Sons, Inc., New York, 1963, p. 436.

6) Y. Maki and K. Kikuchi, Chem. Ind. (London), 1976, 322.

7) A. Nohara, H. Kuriki, T. Saijo, H. Sugihara, M. Kanno, and Y. Sanno, J. Med. Chem., 20, 141 (1977).

8) K. Kondo, N. Tsubota, Y. Ohnishi, and H. Yoshimura, Jpn. J. Parasit., 30, 549 (1981).

9) Results of the screening will be reported elsewhere.

10) Jiang-su-xin-yi-xue-yuan, "Zhong-yao-da-ci-dian (中葯大辞典)," Shang-hai-ren-min-chu-ban-she, Shang-hai, 1977 , p. 2525.

11) G. Nonaka, F. Hsu, and I. Nishioka, J. Chem. Soc., Chem. Commun., 1981, 781.

12) C. Hansh, "Drug Design," Vol. 1, ed. by E. J. Ariens, Academic Press, New York, 1971, pp. $271-342$.

13) H. Kubinyi, Arzneim.-Forsch., 26, 1991 (1976).

14) C. N. Huhtanen, J. Food Protection, 43, 195 (1980).

15) M. Hattori, K. Miyachi, S. Hada, N. Kakiuchi, T. Namba, F. Kiuchi, and Y. Tsuda, Chem. Pharm. Bull., in press. 